\title{
Major differences in the pulmonary circulation between birds and mammals
}

\author{
John B. West, Rebecca R. Watson, and Zhenxing Fu \\ Department of Medicine, University of California San Diego, La Jolla CA 92093-0623
}

\begin{abstract}
The lungs of domestic chickens were perfused with blood or dextran/saline and the pulmonary artery pressure $(\mathrm{Pa})$ and venous pressure $(\mathrm{Pv})$ were varied in relation to air capillary pressure $(\mathrm{PA})$. In zone 3 conditions, pulmonary vascular resistance (PVR) was virtually unchanged with increases in either $\mathrm{Pa}$ or Pv. This is very different from mammals where the same interventions greatly reduce PVR. In zone 2 conditions blood flow was essentially independent of $\mathrm{Pv}$ as in mammalian lungs but all the capillaries appeared to be open, apparently incompatible with a Starling resistor mechanism. In zone 1 the capillaries were open even when PA exceeded Pa by over $30 \mathrm{cmH}_{2} \mathrm{O}$ which is very different behavior from that of the mammalian lung. We conclude that the air capillaries that surround the blood capillaries provide rigid support in both compression and expansion of the vessels. The work suggests a pathogenesis for Pulmonary Hypertension Syndrome in chickens which costs the broiler industry $\$ 1$ billion per year.
\end{abstract}

\section{Keywords}

pulmonary vascular resistance; zones of lung; capillary collapse; Pulmonary Hypertension Syndrome

\section{Introduction}

It is remarkable that the two great classes of vertebrates capable of sustained high oxygen consumptions, the mammals and birds, have radically different lungs. The mammalian lung has reciprocating ventilation with large terminal air spaces (alveoli) while the avian lung has a flow-through system with small air capillaries. As a result the environment of the pulmonary capillaries is very different between the mammals and birds.

\begin{abstract}
Although the general arrangement of the avian pulmonary circulation is similar to that of mammals with the respect to the pulmonary arteries, capillaries, and pulmonary veins, some differences have been described. For example, the avian lung has cross-current gas exchange which has the potential for more efficient gas exchange than the uniform, pool organization of the mammalian lung (Piiper and Scheid 1972). In addition, some birds have an extremely thin blood-gas barrier (BGB). As an example, the harmonic mean thickness of the BGB of the rock martin (Hirundo fuligula) and the violet-eared hummingbird (Colibri caruscans) is less than $0.1 \mu \mathrm{m}$ compared to approximately $0.33 \mu \mathrm{m}$ in the Etruscan shrew (Suncus etruscus), the
\end{abstract}

Correspondence to: John B. West, M.D., Ph.D., UCSD Department of Medicine 0623A, 9500 Gilman Drive, La Jolla, CA 92093-0623, Telephone: 858-534-4192, FAX: 858-534-4812, e-mail: E-mail: jwest@ucsd.edu.

Publisher's Disclaimer: This is a PDF file of an unedited manuscript that has been accepted for publication. As a service to our customers we are providing this early version of the manuscript. The manuscript will undergo copyediting, typesetting, and review of the resulting proof before it is published in its final citable form. Please note that during the production process errors may be discovered which could affect the content, and all legal disclaimers that apply to the journal pertain. 
mammal with the thinnest barrier (Gehr et al. 1980; Dubach 1981; Maina 1984). Even more striking is the fact that the BGB of the avian lung is of uniform thickness around the circumference of the capillary whereas in the typical mammal one side of the capillary is thickened by the presence of a type 1 collagen bundle. This difference stems from the fact that the avian lung with its honeycomb-like structure of air capillaries does not need the type 1 collagen cable that is apparently essential for maintaining the integrity of the alveolar wall in mammals (West et al. 2006). We have proposed that the explanation for the extremely thin blood-gas barrier and the fact that it so uniform in thickness is the mechanical support provided by the dense packing of air capillaries around the blood capillaries in the gas-exchanging regions of the lung.

In addition to these ultrastructural differences between the avian and mammalian lungs some physiological differences have also been described. For example, Powell et al. (1985) measured pulmonary arterial pressure, mean left atrial pressure and cardiac output in anesthetized ducks and showed that temporary occlusion of the pulmonary artery to the left lung resulted in no significant change in pulmonary vascular resistance of the right lung in spite of the fact that the blood flow through it was doubled. Similar experiments showed that unilateral pulmonary artery occlusion approximately doubled total pulmonary vascular resistance (Wideman 2001). This is very different behavior from that seen in mammalian lungs where the same intervention results in a striking fall in pulmonary vascular resistance of the unoccluded lung apparently as a result of recruitment and distension of pulmonary capillaries.

Research on the avian pulmonary circulation can be justified in its own right but there is an additional practical reason. A common disease in broiler chickens apparently associated with rapid gains in weight is Pulmonary Hypertension Syndrome. This is characterized by high pulmonary arterial pressures, ascites, and death, and has been estimated to cost the broiler chicken industry $\$ 1$ billion per year (Currie 1999). The pathogenesis of this condition is not yet fully understood.

Here we describe experiments on the pulmonary circulation of chicken lungs perfused in situ where pulmonary arterial pressure and pulmonary venous pressure were systematically altered in relation to air capillary pressure. The resulting pressure-flow characteristics of the pulmonary circulation and the morphology of the pulmonary capillaries were determined. We are not aware of any previous studies along these lines. The results show dramatic differences between the pulmonary circulation in chickens and mammals.

\section{Methods}

\subsection{Animal Preparations}

The experiments were approved by the Animal Subjects Committee at the University of California, San Diego. A total of 20 white leghorn chickens (Gallus gallus domesticus) weighing 1.3 to $1.8 \mathrm{~kg}$ were anesthetized with IV sodium pentobarbital $(40 \mathrm{mg} / \mathrm{kg})$ and a carotid artery was sectioned for rapid exsanguination after heparinization $(1500 \mathrm{U} / \mathrm{kg})$. For the flow studies the chest was then opened close to the midline and catheters were inserted into the main pulmonary artery via the right ventricle, and the left atrium via the left ventricle. The catheters were secured by thread or tape to ensure that blood could only move from the pulmonary artery to the left atrium through the lung. The catheters were connected to small reservoirs, and saline manometers in the circuit measured both the pulmonary artery and left atrial pressure. Care was taken to remove all bubbles from the circuit and Tygon ${ }^{\circledR}$ tubing was used to connect the catheters to the reservoirs. The reference level for the manometers was set at the level of the lung using a spirit level. 


\subsection{Perfusion Studies}

An initial set of experiments was carried out with blood perfusion by pooling the blood from three chickens and diluting it with an equal volume of 3\% T-70 dextran in saline (350 mOsm). However, subsequent attempts using blood as the perfusion fluid were unsuccessful possibly because of incompatible blood groups. The perfusion was therefore changed to 3\% T-70 dextran in saline and this gave similar results to the initial experiments with blood. For each measurement of blood flow and pulmonary vascular resistance, the reservoirs were set at the chosen level as measured from the saline manometers, and flow rate was measured by collecting a timed sample in the venous reservoir. This reservoir had a short stand pipe which set the level of left atrial pressure and blood flowed out of this into the reservoir where it was collected

\subsection{Morphology Studies}

For the morphology studies the lung was fixed for microscopy either by perfusion fixation or instilling fixative via the trachea. Perfusion fixation was accomplished as previously described in our laboratory (Tsukimoto et al, 1991) by perfusing the lung for 10 min with $2.5 \%$ gluteraldehyde and 3\% T-70 dextran in $0.1 \mathrm{M}$ phosphate buffer (total osmolarity $500 \mathrm{mOsm}$, $\mathrm{pH}$ 7.4) during which time the pulmonary arterial and left atrial pressures were held constant. The lungs were then dissected free and stored in $2.5 \%$ gluteraldehyde at $4^{\circ} \mathrm{C}$ for several days until they were processed. Airway instillation was performed by setting the vascular pressures at the appropriate level and pouring the fixative solution into the trachea from a reservoir set at a predetermined level. Because when the chest was opened, fixative flowed from the large airways through the ostia into the ventral air sac, the reservoir was kept filled for $15 \mathrm{~min}$. Subsequently, the lungs remained in $2.5 \%$ gluteraldehyde at $4{ }^{\circ} \mathrm{C}$ until they were processed.

\subsection{Statistics}

The effects of an intervention such as that of changing pulmonary artery pressure on pulmonary vascular resistance were tested using a paired $t$ test. Significance was accepted at $\mathrm{P}<0.05$.

\section{Results}

\subsection{Flow Studies}

It is convenient to discuss the results in terms of the relations between pulmonary artery $(\mathrm{Pa})$, left atrial or pulmonary venous $(\mathrm{Pv})$, and air capillary $(\mathrm{PA})$ pressure. The last was assumed to be equal to atmospheric pressure when the ventral air sac was opened and because the parabronchi were therefore connected to the atmosphere. Using the zone nomenclature, Zone 1 refers to the situation where $\mathrm{PA}>\mathrm{Pa}>\mathrm{Pv}$; Zone 2 is $\mathrm{Pa}>\mathrm{PA}>\mathrm{Pv}$; Zone 3 is $\mathrm{Pa}>\mathrm{Pv}>\mathrm{PA}$ (West et al, 1964). Note that topographical differences of blood flow in the chicken lung are not considered here because the height of the organ in the supine animal is only about $2 \mathrm{~cm}$. Zone 3 behavior will be discussed first because this is the most likely situation in the live animal.

3.3.1. Zone 3-Fig. 1A shows the changes in pulmonary vascular resistance as pulmonary arterial pressure was altered from 10 to $30 \mathrm{cmH}_{2} \mathrm{O}$ in 12 experiments in 4 chickens. The pulmonary venous pressure was held constant at 5,10 or $15 \mathrm{cmH}_{2} \mathrm{O}$ for these measurements. It can be seen that pulmonary vascular resistance, calculated as $(\mathrm{Pa}-\mathrm{Pv}) / \mathrm{flow}$, showed some variability but no consistent change as pulmonary arterial pressure was increased. The mean change in pulmonary vascular resistance was an increase of about $9 \%$ but this was not significant. 
This nearly constant pulmonary vascular resistance as pulmonary arterial pressure is increased for a fixed pulmonary venous pressure is in dramatic contrast to the behavior of the mammalian lung. For example, Borst et al. (1956) measured the pulmonary vascular resistance of one separately perfused lung in anesthetized dogs when the pulmonary arterial pressure was increased from 12 to $17 \mathrm{mmHg}$ and the left atrial pressure was held constant at $5.9-6.2 \mathrm{mmHg}$. The result was a fall in pulmonary vascular resistance from 0.025 to $0.015 \mathrm{mmHg} \cdot \mathrm{min} . \mathrm{ml}^{-1}$, that is a decrease of about $40 \%$. Similar results have been obtained by other investigators (Lloyd and Wright 1960; Roos et al. 1961).

Fig. 1B shows the effects on pulmonary vascular resistance of raising pulmonary venous pressure from 5 to $15 \mathrm{cmH}_{2} \mathrm{O}$ when pulmonary arterial pressure was held constant at 15,20 , 25 , or $30 \mathrm{cmH}_{2} \mathrm{O}$. These are the results of 15 experiments on 4 chickens. Again there was no consistent change in pulmonary vascular resistance. On the average this fell by about $5 \%$, but the change was not significant.

Again this behavior is in striking contrast to that in mammalian lungs following the same intervention. For example, in the study by Borst et al. (1956) an increase in left atrial pressure from 8.2 to $11.7 \mathrm{mmHg}$ when pulmonary arterial pressure was kept constant at $25.1 \mathrm{mmHg}$ reduced the pulmonary vascular resistance by about $22 \%$. Similar results have been found by other investigators (Haddy and Campbell 1953; Lloyd and Wright 1960; Roos et al. 1961). Because increasing pulmonary arterial pressure at constant venous pressure, and increasing pulmonary venous pressure at constant pulmonary arterial pressure, result in an increase in capillary pressure, the resulting fall in pulmonary vascular resistance is generally believed to be caused by recruitment and distension of pulmonary capillaries. Using morphometric techniques on rapidly frozen dog lung, Glazier et al. (1969) showed that increases in capillary pressure both open up previously closed capillaries, and increased the caliber of capillaries already open.

We also made measurements to determine whether a critical closing pressure exists in the chicken pulmonary circulation. Burton (1951) introduced the term "critical closing pressure" to describe the behavior of blood vessels which, because of inherent tension in their walls, close even when the pressure inside them exceeds the pressure outside. Critical closing pressures of 10-70 $\mathrm{mmHg}$ have been measured in the human forearm by plethysmography. In our cannulated chicken preparation we set the pulmonary venous pressure at $5 \mathrm{cmH}_{2} \mathrm{O}$ and measured the pulmonary arterial pressure until flow ceased. The difference between the pulmonary arterial and venous pressures was within about $2 \mathrm{cmH}_{2} \mathrm{O}$ and so we concluded that the critical closing pressure was negligible. This conclusion is consistent with previous measurements in dogs by Gilbert et al. (1958) and West and Dollery (1965). Borst et al. (1956) reported a critical closing pressure of $7 \mathrm{mmHg}$ in dog lungs but this was probably an artifact caused by the positive alveolar pressure that was being used to ventilate the lung (West and Dollery 1965).

3.1.2. Zone 2-Fig. 2A shows the results obtained when the flow rate was measured as pulmonary venous pressure was reduced from the level of the pulmonary arterial pressure to $15 \mathrm{~cm}$ below the lung, or $-15 \mathrm{cmH}_{2} \mathrm{O}$ with respect to atmospheric pressure. The measurements are from 6 chickens and pulmonary arterial pressure was either 10 or $20 \mathrm{cmH}_{2} \mathrm{O}$. It can be seen that there was no consistent change in flow rate when the pulmonary venous pressure was reduced below air capillary pressure, that is, atmospheric pressure ( 0 on the $\mathrm{x}$ axis). On the average the flow rate fell by about $13 \%$ but the difference was not significant.

The finding that flow did not increase when the pulmonary venous pressure was reduced below air capillary pressure is consistent with the behavior of mammalian lungs in Zone 2 situations, that is, when pulmonary venous pressure is reduced below alveolar pressure. In fact the curves 
are remarkably similar by those obtained by Permutt et al. (1962) in experiments on dog lungs and an example is shown in Fig. 2B. In this plot the vertical broken line indicates when the pulmonary venous pressure was equal to the alveolar pressure. The two lines show the results of both lowering and subsequently raising venous pressure. Note that Fig. 2B shows a slight fall in flow rate as the pulmonary venous pressure was progressively reduced below alveolar pressure. The same tendency is seen in three of the experiments in Fig. $2 \mathrm{~A}$ but the reasons are not understood in terms of the Starling resistor mechanism. Note also that Fig. 2B shows a tendency for flow rates to fall even when pulmonary venous pressure is slightly above alveolar pressure, and that two of the lines in Fig 2A possibly show a similar pattern.

The Zone 2 behavior is sometimes compared with that of a Starling resistor, which is a collapsible thin-walled rubber tube in a pressure chamber, because the flow in such a device is independent of the downstream pressure when the chamber pressure exceeds this pressure (Permutt et al, 1962). The conventional explanation for the lung is that the thin-walled capillaries collapse at their downstream ends and thus limit flow. However this behavior has never been demonstrated morphologically in mammalian lungs and indeed would be very difficult to do because most of the capillaries are open. It was therefore surprising to find that in the chicken lung under Zone 2 conditions apparently all capillaries are wide open as shown in Fig 3. This result suggests that the Zone 2 behavior in the chicken lung results not from collapse of the capillaries but of the small veins emerging from the lung where the surrounding pressure is atmospheric. In fact the observation raises the possibility that the Zone 2 behavior in the mammalian lung is caused by the same mechanism. This has never been disproved.

3.1.3. Zone 1-Experiments were carried out to determine whether there is any flow under Zone 1 conditions, that is $\mathrm{PA}>\mathrm{Pa}>\mathrm{Pv}$. First, the pulmonary venous pressure was held 10 $\mathrm{cmH}_{2} \mathrm{O}$ below air capillary pressure. With a pulmonary arterial pressure of $5 \mathrm{cmH}_{2} \mathrm{O}$, flow occurred, but then stopped when pulmonary arterial pressure had fallen to a value nearly equal to air capillary pressure. In another experiment pulmonary venous pressure and pulmonary arterial pressure were set at -10 and $-5 \mathrm{cmH}_{2} \mathrm{O}$ respectively in relation to air capillary pressure, and no flow occurred. Therefore we concluded that there was no flow under Zone 1 conditions.

This result is not surprising in view of the pressure-flow relations in Zone 2. The fact that flow does not increase as pulmonary venous pressure is reduced below air capillary pressure implies that the low pulmonary venous pressure is not influencing flow because of collapse of some vessels, presumably small veins. However, it is of great interest that many of the capillaries are clearly wide open under Zone 1 conditions as shown in Fig 3.

\subsection{Morphology Studies}

Histological sections were prepared under known physiological conditions so that the morphology of the pulmonary capillaries could be related to the pressure-flow characteristics. The results are summarized in Fig. 3. The three different zone conditions are shown one above the other in the traditional order. However, it should be re-emphasized this is not meant to imply that there are topographical differences within the chicken lung. Rather the three zones represent the three possible combinations of pulmonary arterial pressure, pulmonary venous pressure, and air capillary pressure (or alveolar pressure in the dog).

In Fig 3A the appearance of chicken lung in Zone 1 conditions is shown. Airway fixation was used at a tracheal pressure of $20 \mathrm{cmH}_{2} \mathrm{O}$ while both the pulmonary arterial pressure and pulmonary venous pressure were held at $-15 \mathrm{cmH}_{2} \mathrm{O}$ (that is, the levels of the reservoirs were $15 \mathrm{cmH}_{2} \mathrm{O}$ below the lung). This represents an extreme Zone 1 situation because the transmural pressure of the capillaries is $35 \mathrm{cmH}_{2} \mathrm{O}$ tending to compress them. In spite of this it can be seen that the capillaries are wide open and that they contain large numbers of red blood cells. 
The corresponding conditions in the dog are shown in Fig 3B. This micrograph from Glazier et al. (1969) was prepared by rapid freezing the lung, and the section was taken $24 \mathrm{~cm}$ above the Zone 1-2 junction where pulmonary arterial pressure was equal to alveolar pressure. Therefore the transmural pressure of the capillaries was about $24 \mathrm{cmH}_{2} \mathrm{O}$ in the direction to compress them, which was somewhat less than the capillary transmural pressure in the adjoining chicken lung section. However, the appearances of the two lungs are dramatically different. In the dog, the capillaries are squeezed flat with only a few red cells trapped in the closed capillaries. This appearance is not surprising because the capillaries of the mammalian lung are unsupported at right angles to the alveolar wall, and the capillary walls themselves are typically only $0.2-0.3 \mu \mathrm{m}$ thick in many places. Therefore the capillaries are easily compressed if alveolar pressure exceeds the pressure inside the capillaries.

Figs. $3 \mathrm{C}$ and $\mathrm{D}$ show the appearances for Zone 2 conditions, that is when $\mathrm{Pa}>\mathrm{PA}>\mathrm{Pv}$. The chicken lung (Fig 3C) was prepared by airway fixation with a pulmonary arterial pressure of $10 \mathrm{cmH}_{2} \mathrm{O}$, air capillary pressure of 0 , and pulmonary venous pressure of $-15 \mathrm{cmH}_{2} \mathrm{O}$. Note that all the capillaries appear to be open. However, as pointed out in relation to Fig. 2A, flow under these conditions is independent of pulmonary venous pressure, and this so-called Starling resistor effect is traditionally attributed to collapse of the capillaries at their downstream end where the intracapillary pressure is lowest. The histological appearance does not seem to be compatible with this explanation, although it could be argued that collapse of a small portion of the capillary bed would be easy to overlook. Nevertheless, we think that it is probable that in the chicken, the Zone 2 behavior is caused by collapse of small veins exposed to a pressure close to atmospheric pressure as they emerge from the lung to join the left atrium. In fact this may also be the case in the mammalian lung.

Fig 3D shows the appearance of the dog lung under Zone 2 conditions. The pulmonary arterial pressure was $5 \mathrm{cmH}_{2} \mathrm{O}$ above alveolar pressure, and the pulmonary venous pressure was 10 $\mathrm{cmH}_{2} \mathrm{O}$ below alveolar pressure. Note that there are clearly more open capillaries containing red blood cells compared to that found in zone 1, but the appearance is patchy and in some of the alveolar walls the capillaries are still closed. It has been shown by morphometry that as the pulmonary arterial pressure is increased under these conditions there is an approximately linear increase in the number of red blood cells per unit length of alveolar wall (Glazier et al. 1969).

Figs $3 \mathrm{E}$ and $\mathrm{F}$ show the appearances in Zone 3 conditions. For the chicken (Fig 3E), perfusion fixation was used with pulmonary arterial pressure and pulmonary venous pressures of 20 and $15 \mathrm{cmH}_{2} \mathrm{O}$ respectively and an air capillary pressure of $0 \mathrm{cmH}_{2} \mathrm{O}$. Again all capillaries appear to be open and indeed there does not seem to be much difference between the appearances of this section and the Zone 2 section above it. The section from the dog lung under Zone 3 conditions (Fig 3F) was prepared with pulmonary arterial and pulmonary venous pressures of the 48 and $44 \mathrm{cmH}_{2} \mathrm{O}$ respectively above alveolar pressure. There is profuse filling of the capillaries with red blood cells.

The histological appearances in zones 2 and 3 were also studied using airway fixation and the results are shown in Fig 4. For zone 2 the pressures were $\mathrm{Pa}=20, \mathrm{PA}=15$, and $\mathrm{Pv}=5$ $\mathrm{cmH}_{2} \mathrm{O}$ respectively. For zone 3 the pressures were $\mathrm{Pa}=20, \mathrm{Pv}=20$ and $\mathrm{PA}=15 \mathrm{cmH}_{2} \mathrm{O}$ respectively. Perfusion fixation is preferable to airway fixation in that the pressures are more accurately known during fixation because the dextran/saline perfusate is simply replaced by glutaraldehyde while the pressures are held constant. By contrast, with airway fixation, the pressure relationships are altered when the fixative is administered. However the histological appearances are not so easy to interpret with perfusion fixation because more of the red blood cells are washed out, and it is sometimes difficult to distinguish between the air and blood capillaries. Nevertheless the appearances in Fig 4 are similar to those shown in Figs 3C and E. 


\section{Discussion}

\subsection{Rigidity of the Pulmonary Capillaries in the Chicken}

A striking finding of these studies is the constancy of the pulmonary vascular resistance (PVR) in the face of large changes in pulmonary arterial and pulmonary venous pressures (Fig. 1). In spite of increasing the pulmonary arterial pressure from 10 to $30 \mathrm{cmH}_{2} \mathrm{O}$, or increasing the pulmonary venous pressure from 5 to $15 \mathrm{cmH}_{2} \mathrm{O}$, there is no consistent change in PVR. In fact on the average there was a slight increase in PVR as pulmonary arterial pressure was raised, while there was a slight decrease as pulmonary venous pressure was raised, but in both cases the changes were very small and not statistically significant.

This is very different behavior from that seen in the mammalian lung where both increases in pulmonary arterial pressure or pulmonary venous pressure result in large falls in PVR (Haddy and Campbell 1953; Borst et al. 1956; Lloyd and Wright 1960; Roos et al. 1961). The mechanism of the fall in PVR is believed to be mainly the recruitment and distension of pulmonary capillaries that occurs when the pressure inside them is increased, and this behavior has been demonstrated histologically (Glazier et al. 1969). However, it is also possible that there is some distension of the pulmonary arteries and pulmonary veins themselves that contributes to the fall in PVR.

We have proposed that the honeycomb-like structure of the avian lung supports the pulmonary capillaries against the expanding forces that develop when the capillary pressure is raised. For example, this allows the avian lung to have an extremely thin blood-gas barrier (Watson et al. 2006; West et al. 2006). The mechanical support of the pulmonary capillaries presumably comes from the epithelial struts or bridges that link the air capillaries to the blood capillaries (Klika et al. 1997; Weidner et al. 2002; Watson et al. 2006; West et al. 2006). These struts also apparently prevent expansion of the pulmonary capillaries when the pressure inside them increases as in the experiments shown in Fig 1, and as a result pulmonary vascular resistance remains unchanged in spite of increases in capillary pressure.

The results presented here also indicate that not only does the tissue surrounding the blood capillaries prevent them from expanding, but that it also prevents them from collapsing when the air capillary pressure greatly exceeds the pressure inside the capillaries. The evidence for this is shown in the top panel of Fig. 3A where in spite of a pressure of $35 \mathrm{cmH}_{2} \mathrm{O}$ tending to compress the capillaries, they remain open. This indicates the remarkable mechanical efficiency of the honeycomb-like structure of the air capillaries as a support for the pulmonary capillaries. In essence the avian pulmonary capillaries are rigid tubes that strongly resist either expansion or compression.

If the pulmonary capillaries behave as rigid tubes and flow is laminar, the Poiseuille equation predicts a linear increase in pulmonary arterial pressure as flow is increased. Also the line would be displaced vertically if the pulmonary venous pressure is changed. These predictions follow from the simple equations:

$$
\begin{gathered}
\mathrm{Pa}-\mathrm{Pv}=\mathrm{Q} \cdot \mathrm{R} \\
\text { therefore } \mathrm{Pa}=\mathrm{Pv}+\mathrm{Q} \cdot \mathrm{R}
\end{gathered}
$$

where $\mathrm{Q}$ is the blood flow and $\mathrm{R}$ is pulmonary vascular resistance.

Fig 5 shows the experimental results in 4 chickens. It can be seen that on the average, pulmonary artery pressure rose nearly linearly with flow rate, and the relationship was displaced upward as pulmonary venous pressure was increased consistent with the above equations. However there was a clear tendency for pulmonary artery pressure to rise more rapidly than flow, 
especially at the highest flow rates. This implies an increase in pulmonary vascular resistance which indeed is also seen in Fig 1. The reason for this is not clear. Possibly the assumption of laminar flow on which the equations are based does not hold at high flow rates because of some flow separation, eddy formation, or actual turbulence. This would increase the pressure difference for a given flow rate. Another possibility is that some pulmonary edema occurred in the preparation causing an increased pulmonary vascular resistance.

As referred to earlier, some previous studies are generally consistent with these findings although no one has previously systematically investigated the relationship between pulmonary vascular resistance and pulmonary vascular pressures in birds. Powell et al. (1985) showed that when the pulmonary artery to one lung was occluded, the pulmonary vascular resistance of the other lung was essentially unchanged in spite of the doubling of blood flow through it. Wideman (2001) found similar results. Other investigators looking for evidence of hypoxic pulmonary vascular vasoconstriction in birds concluded that any increase in pulmonary arterial pressure was the result of an increased pulmonary blood flow (Black and Tenney, 1980; Faraci et al. 1984).

We were initially surprised to find so many capillaries wide open in Zone 1 (Fig. 3) but we should not have been. The time-honored method of studying the morphology of the avian lung is to pour fixative into the trachea and maintain a pressure of about $20 \mathrm{cmH}_{2} \mathrm{O}$ while the lung is fixed. Since the heart is not beating the pulmonary vascular pressures are presumably close to atmospheric pressure resulting in a Zone 1 situation, but excellent fixation of full capillaries is obtained.

Finally a fascinating question is what happens to pulmonary arterial pressure during intense exercise such as flying when the cardiac output must increase greatly. The prediction from this work is that the pressure would rise very substantially but apparently no measurements have yet been made under these conditions.

\subsection{Why is the Environment of the Pulmonary Capillaries so Different between Birds and Mammals?}

We have seen that the pulmonary capillaries in the chicken are closely surrounded by air capillaries which strongly support them both in compression and expansion. Why is the microanatomy so different from that found in mammals? Our contention is that the differences in the two environments are the inevitable result of the different modes of ventilation in the two classes of vertebrates as shown in Fig 6. In mammals, the reciprocating nature of ventilation requires the terminal air spaces (alveoli and alveolar ducts) to be relatively large because inspired gas has to reach the most distal alveoli by a combination of convection and diffusion, and the resistance to flow must be kept low. By contrast, in the avian lung with its flow-through system, the terminal air spaces (air capillaries) can afford to be very small. The result is that the support of the capillaries at right angles to the alveolar wall is virtually non-existent in mammals but in birds the capillaries are supported all around their circumference. An advantage of this arrangement for the bird is that the blood-gas barrier can be extremely thin and of uniform thickness (Watson et al. 2006; West et al. 2006). However a disadvantage is a propensity for pulmonary hypertension.

\subsection{Implications for the Pulmonary Hypertension Syndrome of Chickens}

Pulmonary Hypertension Syndrome is a disease of fast-growing broiler chickens that is characterized by pulmonary hypertension and ascites leading to death. It is a serious problem in the broiler industry with estimated costs of $\$ 1$ billion per year (Currie 1999). There is a voluminous literature on the topic and useful reviews are in Currie (1999) and Wideman (2001). Many causative factors have been implicated including hypoxia, cold temperature, and 
nutritional status. One theory is that hypoxemia is responsible for the pulmonary hypertension as a result of pulmonary vasoconstriction (Peacock et al. 1989). However, in spite of a great deal of research the pathogenesis of the condition is not fully understood.

The results presented here show that the capillaries of the chicken lung behave as rigid tubes and that pulmonary arterial pressure rises linearly with pulmonary blood flow or even more rapidly with fast flow rates (Fig 5). Therefore pulmonary hypertension is inevitable if there is an increase in cardiac output. Furthermore any increase in the filling pressure of the left side of the heart as occurs when cardiac output is increased will raise the pulmonary venous pressure and thus exaggerate the increase in pulmonary artery pressure as shown in Fig 5. The severe pulmonary hypertension will lead to right heart failure, ascites, and possibly death. This sequence of events seems likely to be the clue to the disease. Why cardiac output increases inappropriately in these birds is not clear but it is presumably related in some way to the measures that are taken to cause rapid growth and therefore plump chickens. Perhaps there is dissociation between the size of the skeletal muscles and the lung resulting from selective breeding as has previously been suggested by Powell (2003). There is some evidence that selecting chickens that are not prone to the disease for breeding lessens the incidence of the condition (Wideman, 2001). However, the likely root cause seems to be the curious physiology of the normal avian pulmonary circulation where the capillaries behave as rigid tubes and any increase in cardiac output or pulmonary venous pressure invariably results in pulmonary hypertension.

\section{Acknowledgements}

The work was supported by NIH grant R01 HL 60968. We thank two anonymous Reviewers for helpful comments on this manuscript.

\section{References}

Black CP, Tenney SM. Pulmonary hemodynamic responses to acute and chronic hypoxia in two waterfowl species. Comp Biochem Physiol 1980;67A:291-293.

Borst HG, McGregor M, Whittenberger JL, Berglund E. Influence of pulmonary arterial and left atrial pressures on pulmonary vascular resistance. Circ Res 1956;4:393-399. [PubMed: 13330181]

Burton AC. On the physical equilibrium of small blood vessels. Am J Physiol 1951;164:319-329. [PubMed: 14810937]

Currie RJW. Ascites in poultry: recent investigations. Avian Path 1999;28:313-326. [PubMed: 16147559]

Dubach M. Quantitative analysis of the respiratory system of the house sparrow, budgerigar, and violeteared hummingbird. Respir Physiol 1981;46:43-60. [PubMed: 7330491]

Faraci FM, Kilgore DL Jr, Fedde MR. Attentuated pulmonary pressor response to hypoxia in bar-headed geese. Am J Physiol 1984;247 Reg Integ Comp Physiol 16:R402-R403.

Gehr P, Sehovic S, Burri PH, Claasen H, Weibel ER. The lung of shrews: morphometric estimation of diffusion capacity. Respir Physiol 1980;40:33-47. [PubMed: 7394364]

Gil J, Bachofen H, Gehr P, Weibel ER. Alveolar volume-surface area relation in air- and saline-filled lungs fixed by vascular perfusion. J Appl Physiol 1979;47:990-1001. [PubMed: 511725]

Gilbert RP, Hinshaw LB, Kuida H, Visscher MB. Absence of a general critical closing pressure in the isolated perfused lung. Am J Physiol 1958;194:160-164. [PubMed: 13559444]

Glazier JB, Hughes JMB, Maloney JE, West JB. Measurements of capillary dimensions and blood volume in rapidly frozen lungs. J Appl Physiol 1969;26:65-76. [PubMed: 5762878]

Haddy FJ, Campbell GS. Pulmonary vascular resistance in anesthetised dogs. Am J Physiol 1953;172:747-751. [PubMed: 13030812]

Klika E, Scheuerman DW, De Groodt-Lassel MH, Bazantova I, Switka A. Anchoring and support system of pulmonary gas-exchange tissue in four bird species. Acta Anat 1997;159:34-41.

Respir Physiol Neurobiol. Author manuscript; available in PMC 2009 May 13. 
Lloyd TC Jr, Wright GW. Pulmonary vascular resistance and vascular transmural gradient. J Appl Physiol 1960;15:241-245. [PubMed: 14417732]

Maina JN. Morphometrics of the avian lung: 3. The structural design of the passerine lung. Respir Physiol 1984;55:291-307. [PubMed: 6739986]

Peacock AJ, Pickett C, Morris K, Reeves JT. The relationship between rapid growth and pulmonary hemodynamics in the fast-growing broiler chicken. Am Rev Respir Dis 1989;139:1524-1530. [PubMed: 2524982]

Piiper J, Scheid P. Maximum gas transfer efficacy of models for fish gills, avian lungs and mammalian lungs. Respir Physiol 1972;14:115-124. [PubMed: 5042148]

Permutt S, Bromberger-Barnea B, Bane HN. Alveolar pressure, pulmonary venous pressure and the vascular waterfall. Med Thorac 1962;19:239-260. [PubMed: 13942495]

Powell FL. Functional genomics and comparative physiology of hypoxia. Ann Rev Physiol 2003;65:203230. [PubMed: 12471168]

Powell FL, Hastings RH, Mazzone RW. Pulmonary vascular resistance during unilateral pulmonary artery occlusion in ducks. Am J Physiol 1985;249:R34-R43.

Roos A, Thomas LJ Jr, Nagel EL, Prommas DC. Pulmonary vascular resistance as determined by lung inflation and vascular pressures. Am J Physiol 1961;16:77-84.

Tsukimoto K, Mathieu-Costello O, Prediletto R, Elliott AR, West JB. Ultrastructural appearances of pulmonary capillaries at high transmural pressures. J Appl Physiol 1991;71:573-582. [PubMed: 1718936]

Watson RR, Fu Z, West JB. Morphometry of the extremely thin pulmonary blood-gas barrier in the chicken lung. Am J Physiol Lung Cell Mol Physiol. 2006 November 17;10.1152/ajplung.00355.2006

West JB, Dollery CT. Distribution of blood flow and the pressure-flow relations of the whole lung. J Appl Physiol 1965;20:175-183.

West JB, Dollery CT, Naimark A. Distribution of blood flow in isolated lung: relation to vascular and alveolar pressures. 1964;19:713-724.

West JB, Watson RR, Fu Z. The honeycomb-like structure of the bird lung allows a uniquely thin bloodgas barrier. Respir Physiol Neurobiol 2006;152:115-118. [PubMed: 16431166]

Wideman RE. Pathophysiology of heart/lung disorders: pulmonary hypertension syndrome in broiler chickens. World's Poultry Science J 2001;57:289-307.

Weidner WJ, Kinnision JR. Effect of extracellular fluid volume expansion on the interparabronchial septum of the avian lung. J Comp Pathol 2002;127:219-222. [PubMed: 12354536] 

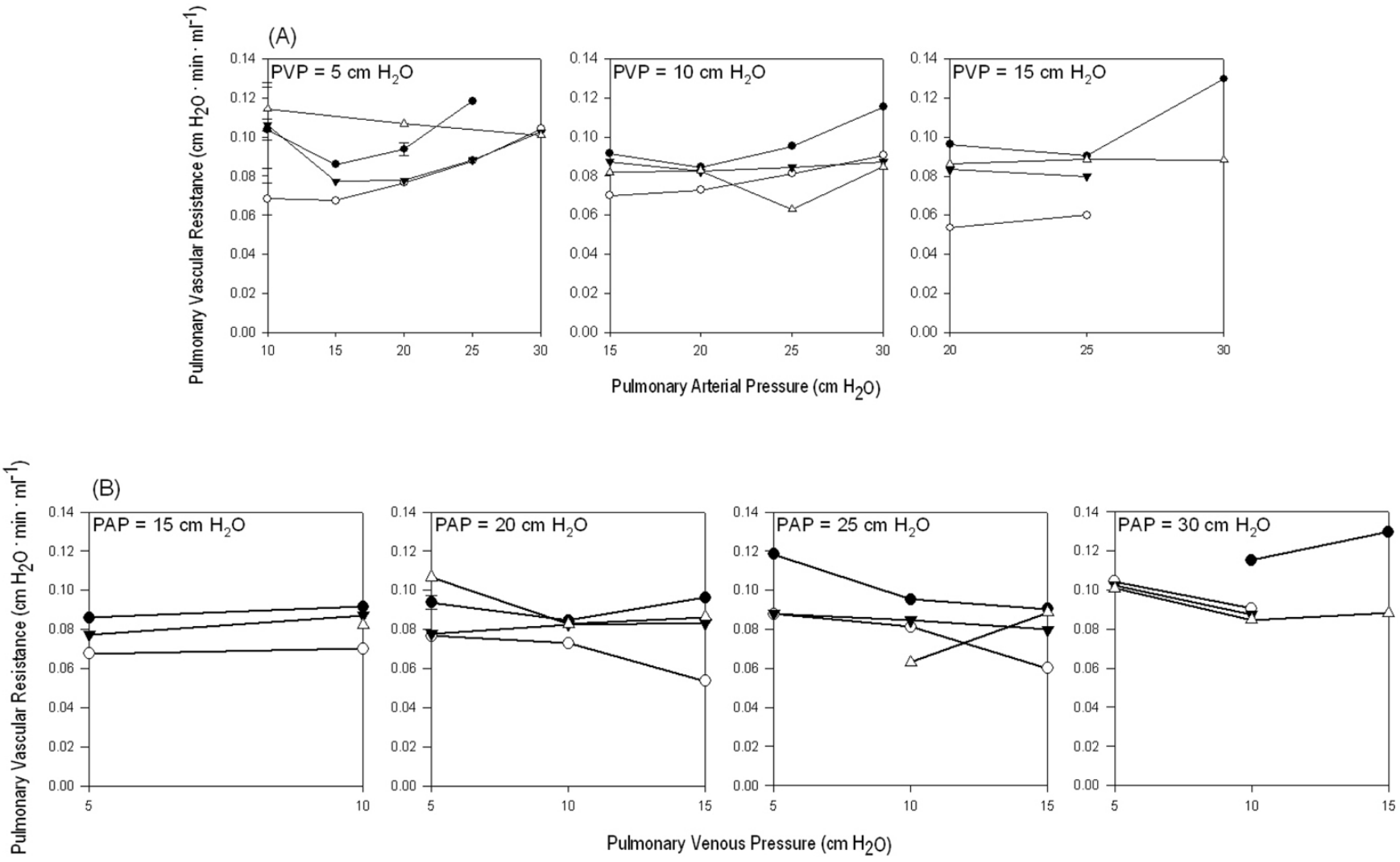

Fig. 1.

Effects of changing pulmonary arterial pressure and pulmonary venous pressure on pulmonary vascular resistance. Each series of symbols represents an individual chicken. In A, pulmonary arterial pressure was increased for 3 fixed levels of pulmonary venous pressure. In B, pulmonary venous pressure was increased for 4 fixed values of pulmonary arterial pressure. There was some variability but no consistent change in resistance. 
(A)

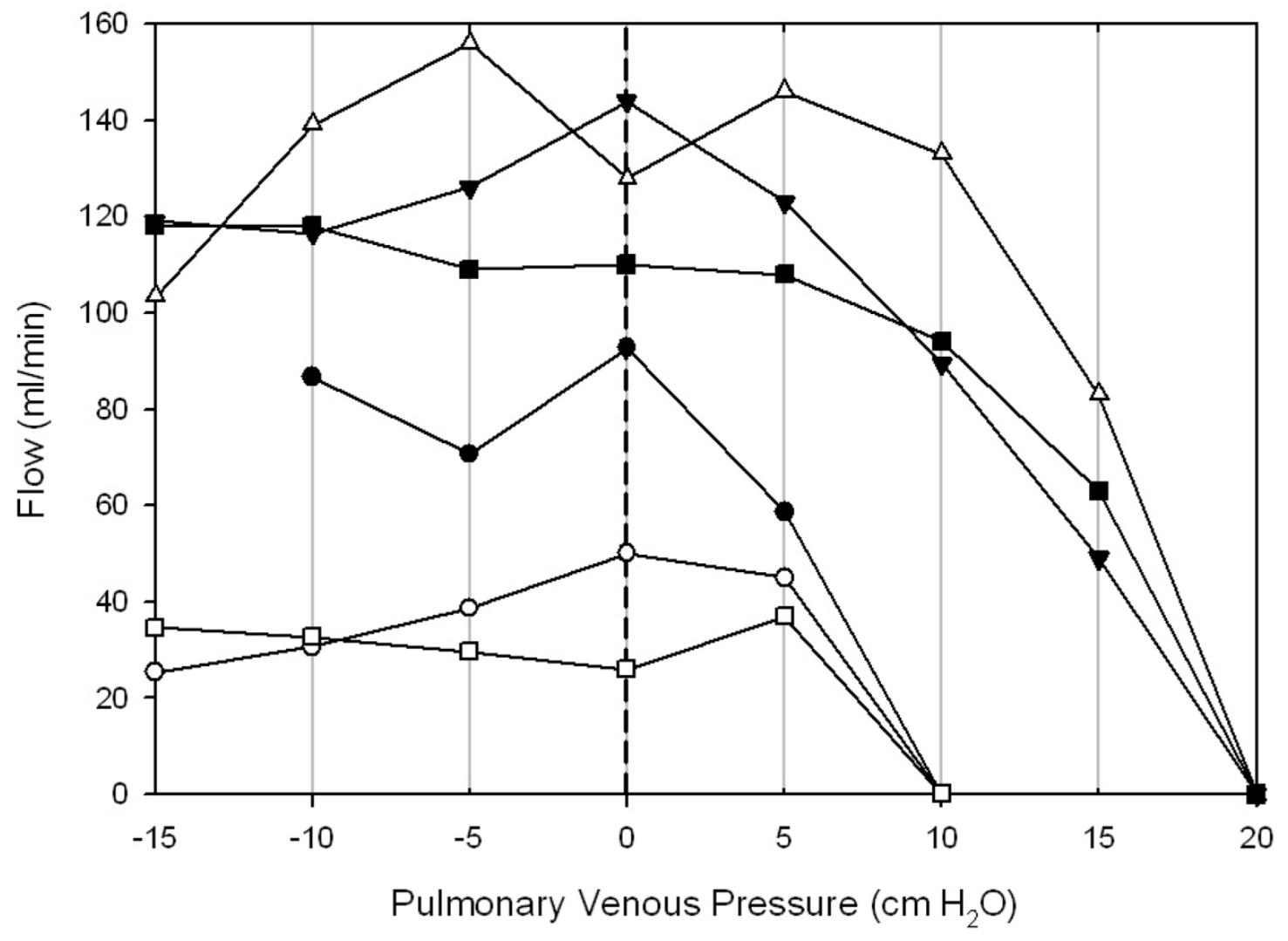




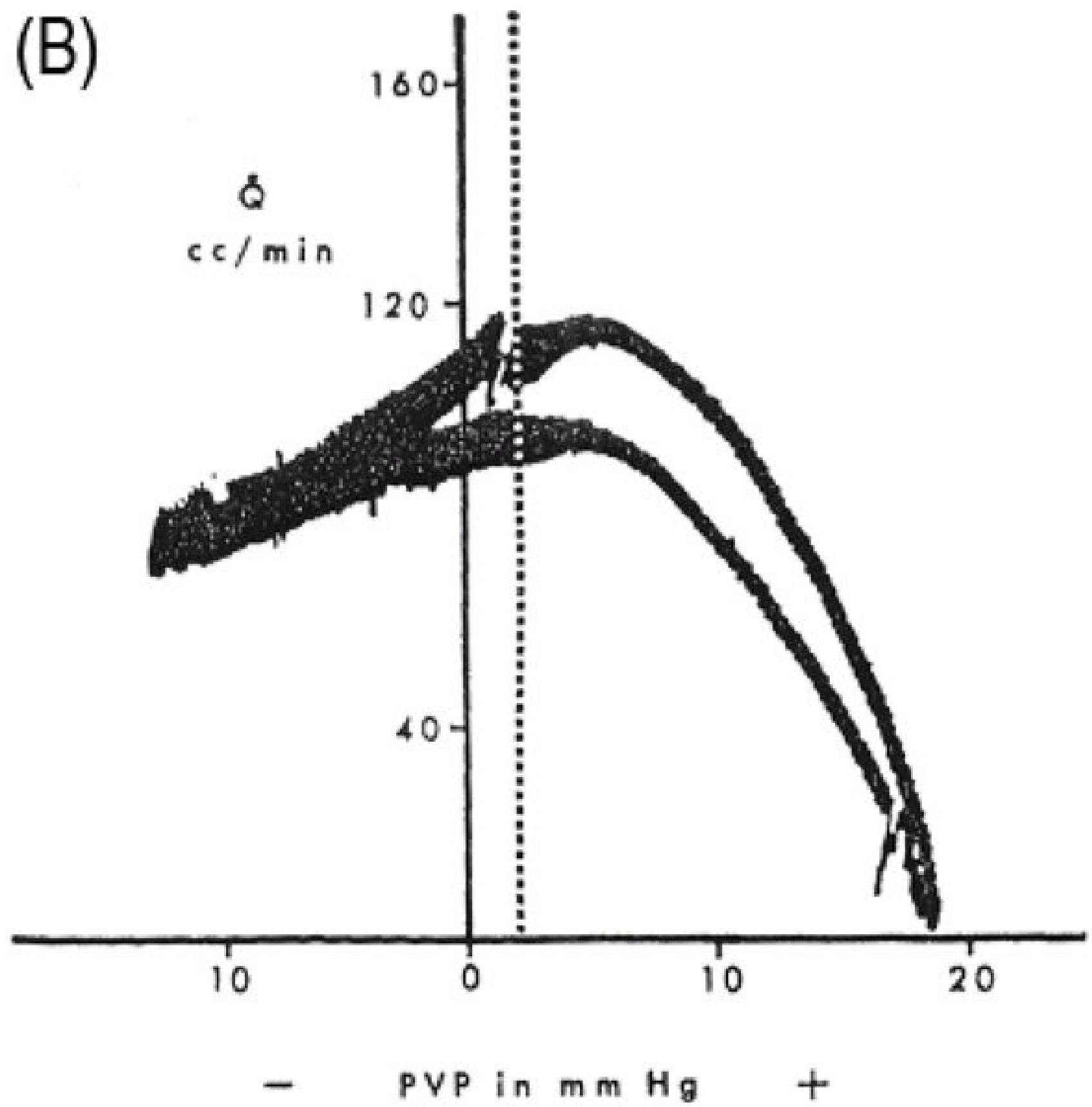

Fig. 2.

Fig. 2A. Effects of changing pulmonary venous pressure on flow rate. Each series of symbols represents an individual chicken. When the venous pressure was reduced below air capillary pressure (indicated by the vertical broken line) there was some variability but no consistent change in flow rate under these Zone 2 conditions. For venous pressures above air capillary pressure, increasing the venous pressure reduced the flow rate.

Fig. 2B. Results obtained in a dog lung when the pulmonary venous pressure was reduced below alveolar pressure (indicated by the vertical broken line). The lower curve was obtained first as venous pressure was raised; the upper curve was then obtained as venous pressure was 
lowered. In both instances there was no increase in flow in spite of a reduction in venous pressure. From Permutt et al. (1962). 


\section{Chicken}

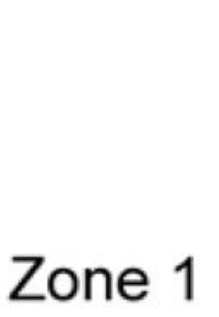

Zone 2

Zone 3
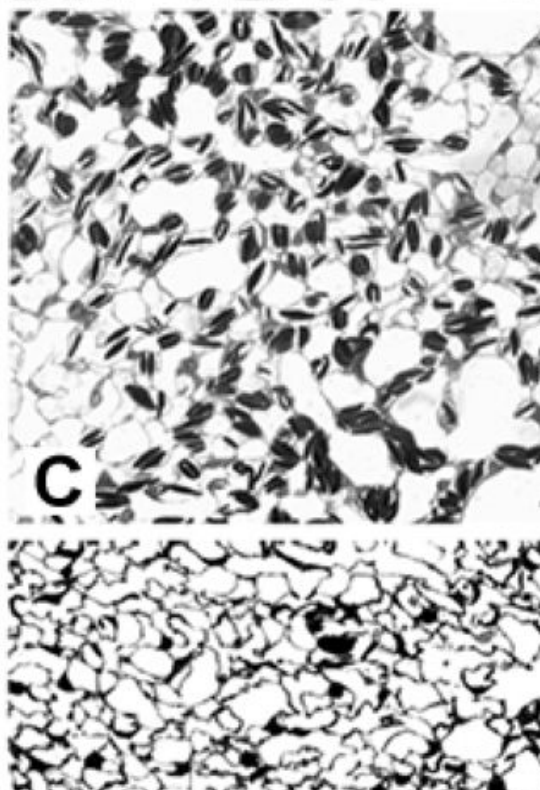

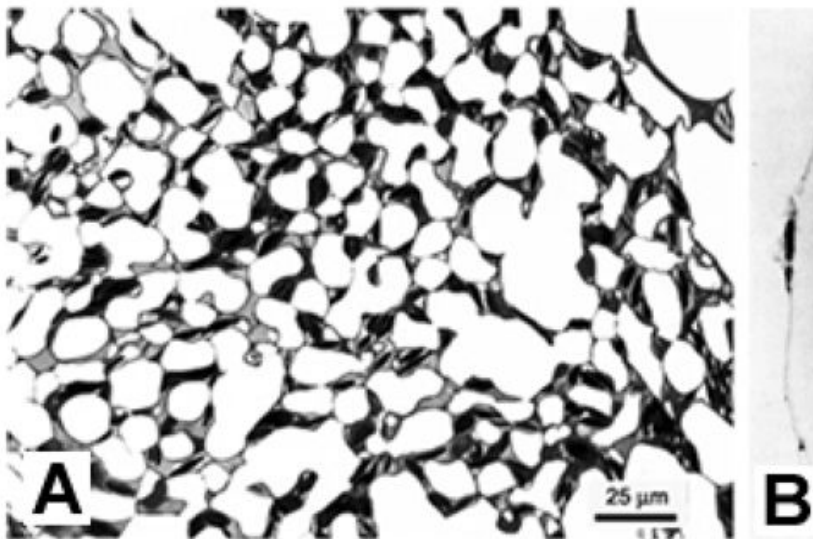

Dog
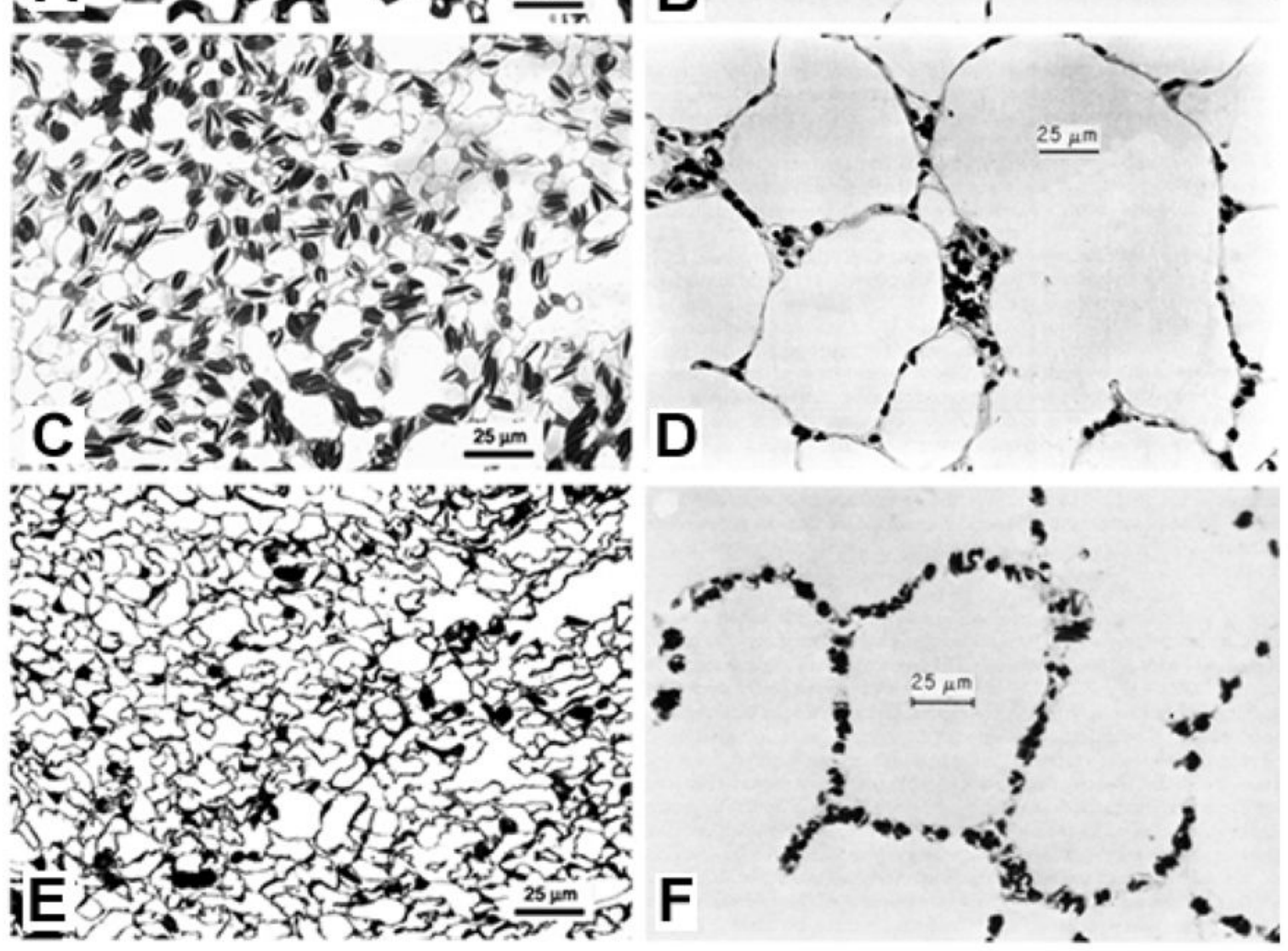

Fig. 3.

Morphology of chicken and dog lungs in Zones 1, 2 and 3. Note that in the chicken lung the capillaries are wide open in all three zones. However, in the dog lung the capillaries are closed in Zone 1, there is patchy filling in Zone 2, and there is profuse filling of the capillaries in Zone 3. See text for details. The micrographs of dog lung are from Glazier et al. (1969). 


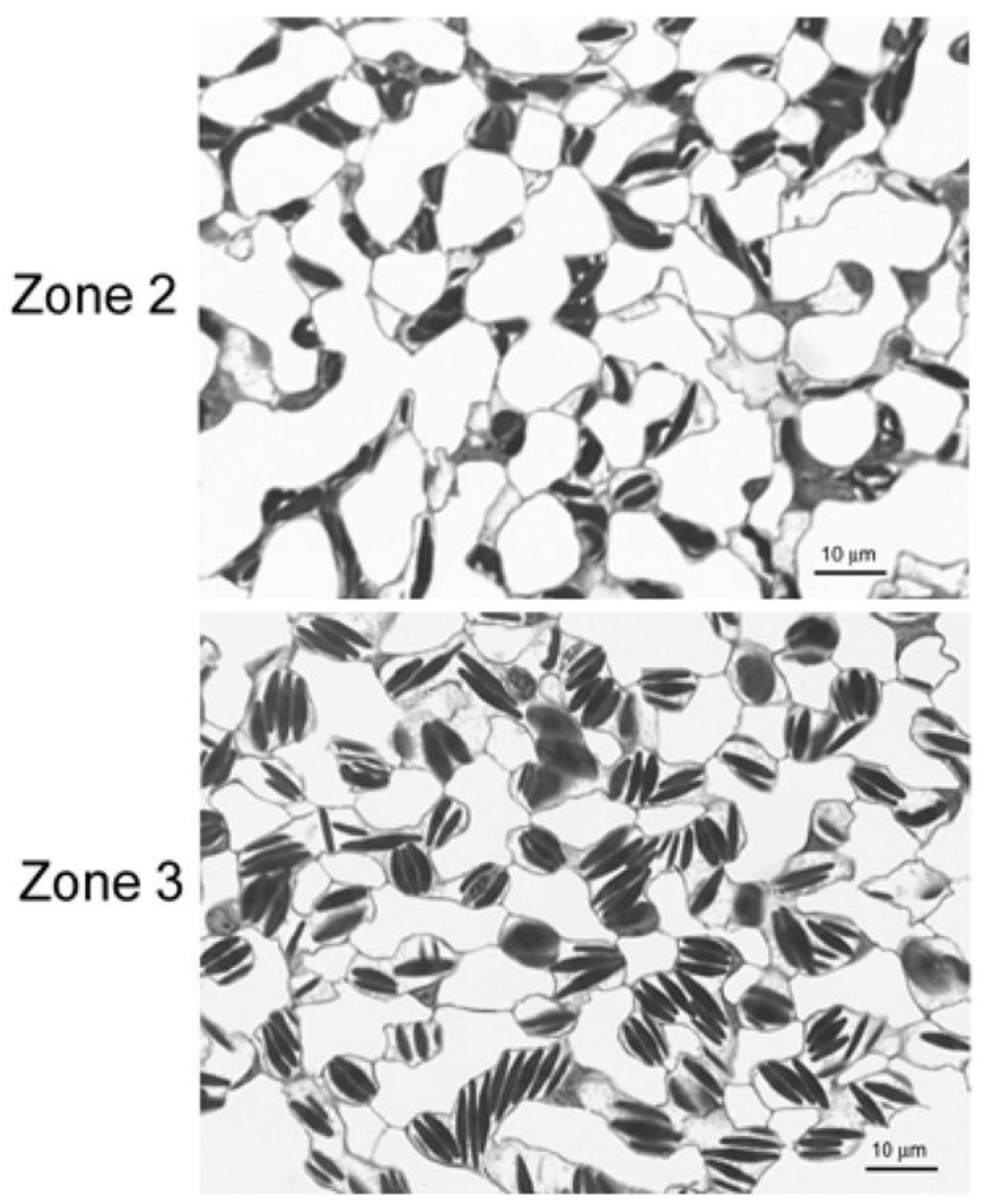

Fig. 4.

Morphology of chicken lung in Zones 2 and 3 following airway fixation. These appearances can be compared with those in Figs. 3C and E which were obtained by perfusion fixation. 

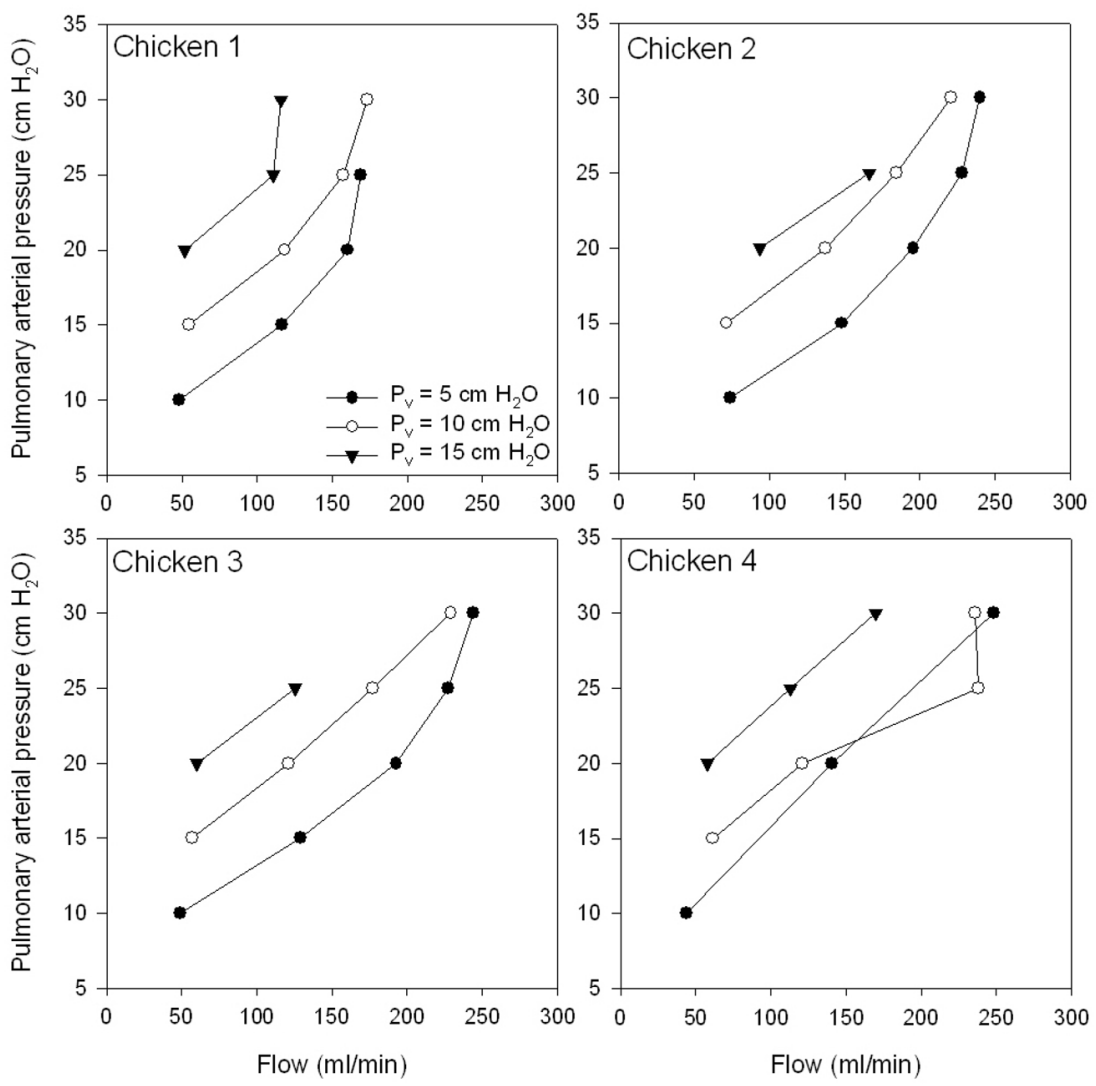

Fig. 5.

Examples of the increase in pulmonary arterial pressure as flow rate was increased for different fixed pulmonary venous pressures. This behavior stems from the fact that the capillaries behave as rigid tubes but the pressure actually rises faster at high flow rates. This may be the basis of the Pulmonary Hypertension Syndrome in fast-growing broiler chickens. 
MAMMAL

\section{Ventilation}

Terminal air spaces

Support of capillaries

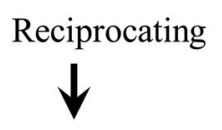

Large (alveoli)

$\downarrow$

Weak
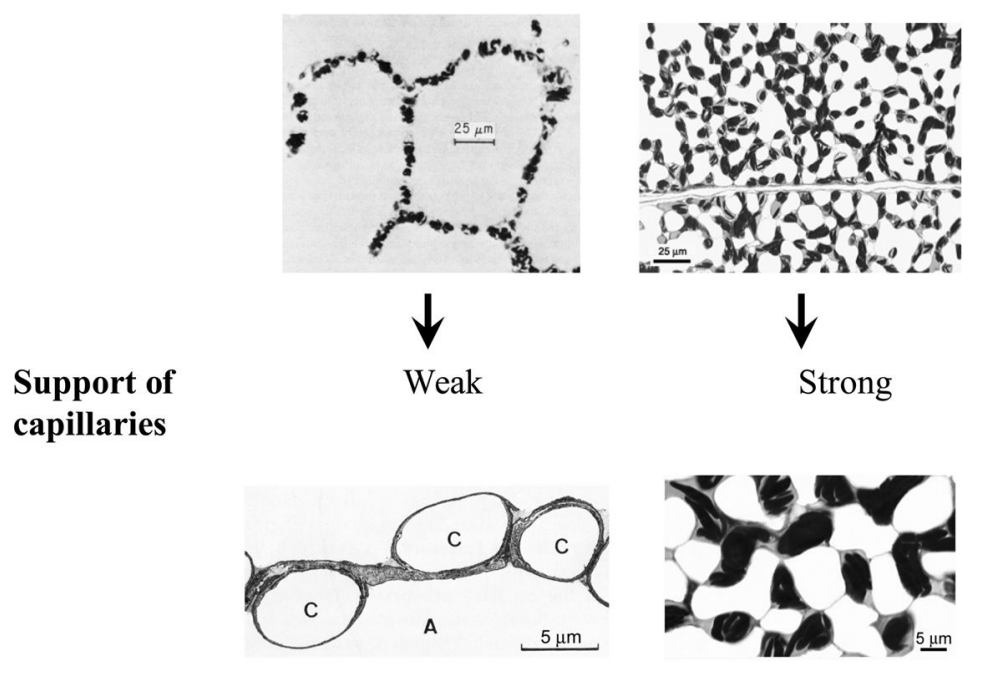

\section{BIRD}

Flow-through

$\downarrow$

Small (air capillaries)

Fig. 6.

Diagram to explain why the different behavior of the pulmonary capillaries in mammals and birds is an inevitable consequence of the different modes of ventilation. See text for details The image at bottom left is from Gil et al (1979). 